\title{
Design of Line/Motor Side Capacitors for PWM CSR-CSI Drives to Achieve Optimal Power Factor in High Power Fan/Pump Applications
}

\author{
$\begin{array}{lll}\text { Y. Xiao and B.Wu N. R. Zargari } & \text { R. Sotudeh** }\end{array}$ \\ Dept. of Electrical and Computer Engineering \\ Ryerson Polytechnic University, Toronto, Canada M5B 2K3 \\ *Allen-Bradley Canada \\ Cambridge, Canada N1R 5X1 \\ **Dept. of Electronics and Computer Engineering \\ University of Teesside, Middlesbrough Cleveland, U.K. TS1 3BA
}

\begin{abstract}
The input power factor of GTO PWM current source rectifiers using a delay angle control scheme is investigated. It is discovered that with an optimal design of line and motor side capacitors for CSRCSI induction motor drives having fan/pump loads, the input power factor is close to unity ( over 0.95 for $30 \%$ to $100 \%$ of rated load ). The concept of near unity power factor operation is presented. The procedures for the capacitor design are discussed. A switching pattern suitable for the delay angle control with a low harmonic distortion is also introduced. The line current of the rectifier is near sinusoidal due to the use of the switching pattern and line side capacitor. Experimental results on a 5 hp drive are given to verify the theoretical analysis.
\end{abstract}

\section{Introduction}

GTO current source inverter based induction motor drivers are often used in petrochemical industry, mining and metals industry, water pumping systems and utility plants to drive high power fans and pumps. In these applications, SCR rectifiers are usually used as a front end converter[1,2]. The SCR rectifier, however, produces harmonics into the power systems and its power factor is poor under light load conditions.

These problems can be solved by replacing the SCR rectifier with a GTO PWM current source rectifier (CSR) as shown in Fig. 1. A line side capacitor is required by the rectifier to provide a current path for the energy stored in the line reactor when a GTO device is turned off. The ac input current of the rectifier is modulated to eliminate certain harmonics while the dc output current is controlled by modulation index $M_{d}[3,4]$.

In general, the GTO current source rectifier produces a leading power factor due to the line capacitor. To achieve unity or maximum power factor operation, a delay angle $\alpha$ between the rectifier input voltage and modulated current should be introduced to generate a lagging current component

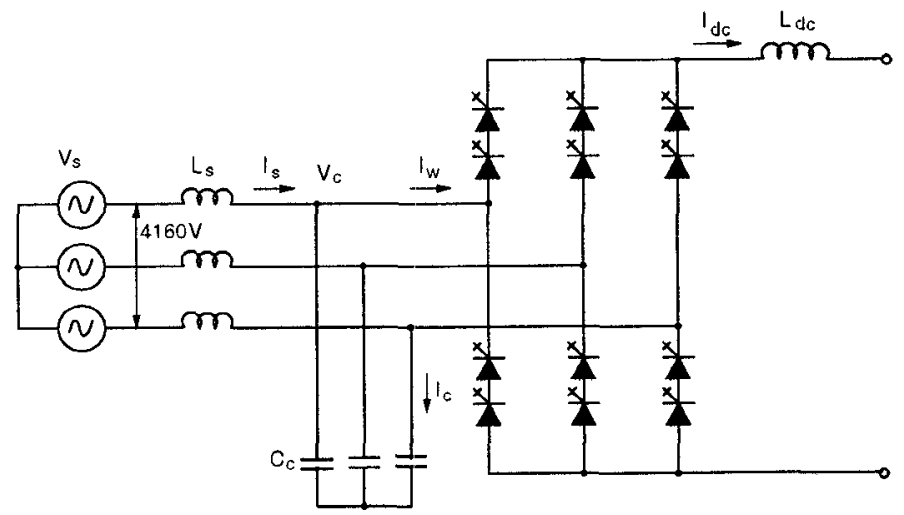

Fig. 1 Circuit diagram of GTO PWM current source rectifier

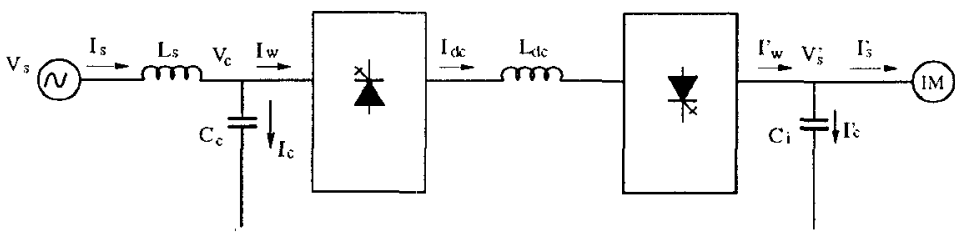

Fig. 2 A GTO CSR-CSI induction motor drive system

which compensates the leading current produced by the capacitor. Integrating the $\alpha$ control with modulation index $\mathrm{M}_{\mathrm{d}}$ control makes the control scheme complicated. For example, both feedforward and feedback techniques should be used to implement the $a$ plus $\mathrm{M}_{d}$ control scheme[5,6].

In this paper, the input power factor of the CSR using the delay angle control only is investigated. It is discovered that with an optimal design of line and motor side capacitors for the CSR-CSI induction motor drives having fan/pump loads (Fig. 2), the input power factor can be kept at least 0.95 over a normal drive operating range. Furthermore, the PWM rectifier using the $\alpha$ control scheme has the following additional features:

- The switching frequency is only $300 \mathrm{~Hz}$, which is the 
lowest switching frequency for 5 th and 7 th harmonic elimination. Therefore, the GTO and snubber losses are minimized;

- The control for the PWM rectifier is simple and easy to implement. The modulation index control is no longer required; and

- The total harmonic distortion generated by this switching pattern is much lower than that by other patterns. The use of this switching pattern and line side capacitor makes the line current near sinusoidal.

\section{Switching Pattern and Rectifier Control}

One of the basic requirements for the switching pattern used in high power converters is that the switching frequency should be minimized to accommodate the GTO switching characteristic and to reduce GTO switching/snubber losses. A switching pattern suitable for the current source rectifier using delay angle control is proposed. A comparison between the delay angle $\alpha$ control and modulation index $M_{d}$ control is given in Table 1 . Obviously, the $\alpha$ control is superior to the $M_{d}$ control because of its lower switching frequency, fixed switching angles and low harmonic distortion.

Table 1 Comparison of switching patterns between $\alpha$ and $M_{d}$ controls

\begin{tabular}{|c|c|c|c|}
\hline \multicolumn{2}{|c|}{ Control scheme } & $\alpha$ control & $\mathrm{M}_{\mathrm{d}}$ control \\
\hline \multicolumn{2}{|c|}{ Switching frequency $(\mathrm{Hz})$} & 300 & 360 \\
\hline \multicolumn{2}{|c|}{ Switching angles } & Fixed & Variable \\
\hline \multicolumn{2}{|c|}{ Harmonic eliminated } & 5 th $\& 7$ th & 5 th $\& 7$ th \\
\hline \multirow{4}{*}{$\begin{array}{l}\text { Harmonic } \\
\text { contents (\%) }\end{array}$} & 11 th & $\begin{array}{c}23.3 \\
\text { (fixed) } \\
\end{array}$ & $\begin{array}{c}56.3 \\
(\max .) \\
\end{array}$ \\
\hline & 13 th & 28.6 & 29.3 \\
\hline & 17 th & 15.8 & 15.8 \\
\hline & 19 th & 0.8 & 27.4 \\
\hline
\end{tabular}

\section{Power Factor Analysis}

The input power factor of the drive system is mainly determined by the line and motor side capacitors, the delay angle $\alpha$ and the load profile of the induction motor. For a fan and pump type of loads, the load torque and power are proportional to the second and third power of the motor speed. In the follows, a set of equations are derived to assist the analysis of input power factor of the drive system.

\section{Motor Side Equations}

Assuming that the air gap flux of the induction motor is kept constant during operation, neglecting the effect of stator resistance and leakage inductance, the air gap flux can be expressed as

$$
\lambda_{s}=\frac{V_{s}^{\prime}}{\omega_{s}}=1 \quad p u
$$

From which

$$
V_{s}^{\prime}=\omega_{s}
$$

where $V_{s}^{\prime}$ is the stator voltage and $\omega_{s}$ is the stator (operating) frequency, all in per unit.

For fan or pump applications, the torque is proportional to the speed square. Assuming at the rated speed, the torque is also rated, the torque-speed relationship can be described by

$$
T=\omega_{s}^{2} \quad p u
$$

Neglecting all the losses in the drive system, the real power required from the inverter is

$$
P=T_{s} \omega_{s}=\omega_{s}^{3} \quad p u
$$

from which the stator current can be calculated:

$$
I_{s}^{\prime}=\frac{P}{V_{s}^{\prime} \cos \phi}=\frac{\omega_{s}^{2}}{\cos \phi} p u
$$

where $\phi$ is the power factor angle of the motor. The real and imaginary components of the stator current are

$$
I_{s, r}^{\prime}=I_{s}^{\prime} \cos \phi=\omega_{s}^{2}
$$

and

$$
I_{s, r}^{\prime}=I_{s}^{\prime} \sin \phi=\omega_{s}^{2} \tan \phi
$$

The capacitor current can be calculated by

$$
I_{c}^{\prime}=\omega_{s} C_{i} V_{s}^{\prime}=\omega_{s}^{2} C_{i}
$$


Thus, the inverter output current is

$$
I_{w}^{\prime}=\omega_{s}^{2} \sqrt{1+\left(C_{i}-\tan \phi\right)^{2}}
$$

\section{Line Side Equations}

As mentioned earlier, a fixed PWM switching pattern is proposed for the rectifier to eliminate 5 th and 7 th while the dc link current $I_{d}$ is controlled by the delay angle $\alpha$. Therefore, the rectifier side modulation index, defined by

$$
M_{d}=\frac{I_{w}}{I_{d}}
$$

is fixed. On the motor side, the inverter output current $I_{w}^{\prime}$ is proportional to the dc link current, whereas the use of the PWM technique is only for the harmonic elimination. Hence the inverter modulation index $\left(M_{d}^{\prime}=I_{w}^{\prime} / I_{d}\right)$ can also be considered constant and equal to line side modulation index, which results in

$$
I_{w}=I_{w}^{\prime}=\omega^{2} \sqrt{1+\left(C_{i}-\tan ^{-1} \phi\right)^{2}}
$$

According to the rectifier phasor diagram shown in Fig. 3, the real (input) power of the rectifier is

$$
P=V_{s} I_{w} \cos \alpha
$$

from which

$$
\begin{gathered}
\cos \alpha=\frac{P}{V I_{w}}=\frac{P}{I_{w}} \\
=\frac{\omega_{s}}{\sqrt{1-\left(C_{i}-\tan ^{-1} \phi\right)^{2}}}
\end{gathered}
$$

where $V_{s}=1.0 \mathrm{pu}$. Assuming the motor power factor is unity for simplicity, Eq. (13) can be rewritten as

$$
\cos \alpha=\frac{\omega_{s}}{\sqrt{1+C_{i}^{2}}}
$$

From Eqs. (11) and (14), the real and imaginary components of $I_{w}$ can be evaluated by

$$
I_{w, r}=I_{w} \cos \alpha=\omega_{s}^{3}
$$

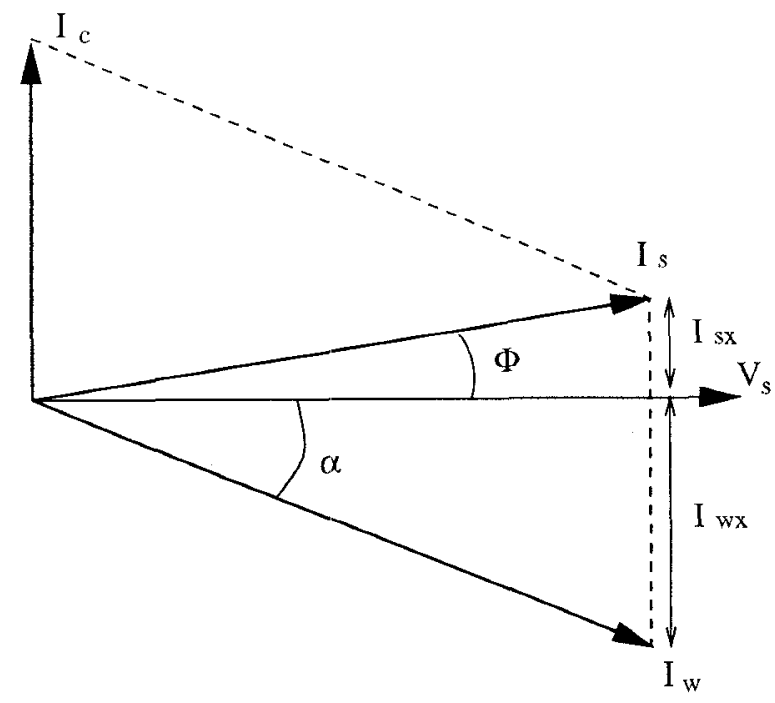

Fig. 3 Phasor diagram of PWM current source rectifier

and

$$
\begin{array}{r}
I_{w, x}=I_{w} \sin \alpha=I_{w} \sqrt{1-\cos ^{2} \alpha} \\
=\omega_{s}^{2} \sqrt{1+C_{i}^{2}-\omega_{s}^{2}}
\end{array}
$$

Finally, the reactive component of the source current can be calculated by

$$
\begin{aligned}
I_{s, x} & =V_{s} \omega C_{s}-I_{w, x} \\
& =C_{c}-\omega_{s}^{2} \sqrt{1+C_{i}^{2}-\omega_{s}^{2}} \quad p u
\end{aligned}
$$

where $\omega$ is the frequency of source voltage, which is equal to $60 \mathrm{~Hz}(1.0 \mathrm{pu})$.

To achieve unity input power factor at motor rated operating point where $\omega_{\mathrm{s}} \approx 1$, the reactive component given in Eq. (17) should be zero, from which the relationship between line and motor side capacitances can be obtained:

$$
C_{c}=C_{i}
$$

It is very interesting to note that the reactive component of the line current does not change much over a certain operation range, which implies that the input power factor can be kept close to unity. For example, assuming that the drive is operated at $40 \%$ of the load with $C_{c}=C_{i}$ per unit, the reactive component is 


$$
\begin{aligned}
I_{s, x} & =0.4-0.74^{2} \sqrt{0.4^{2}+1-0.74^{2}} \\
& =0.028 \mathrm{pu}
\end{aligned}
$$

and the corresponding input power factor is 0.997 .

The concept of power factor control is further illustrated in Fig. 4, where the motor capacitor is 0.6 per unit and motor power factor is assumed to be unity. The input power factor varies with the line capacitor size and motor output power. The best power factor profile can be obtained when the line capacitor size is made equal to that of the motor capacitor.

Figure 5 shows the input power factor profile where the system parameters remain the same as given in Fig. 4 except that the rated motor power factor is 0.9 . A good input power factor profile can be obtained when a smaller size of the line capacitor is selected ( $C_{c}=0.4$ per unit in this case ).

The design of the capacitors involves two steps. The first step is to determine the motor side capacitor. The size of this capacitor is mainly dependent on inverter switching frequency. For a drive system with a switching frequency of $180 \mathrm{~Hz}$, the capacitor value of 0.4 to $0.7 \mathrm{pu}$ will make the motor current and voltage waveforms nearly sinusoidal [1]. Considering the fact that the line capacitor should be smaller than motor capacitor to achieve a good power factor profile as shown in Fig. 5, a motor capacitor value close to its upper limit ( 0.6 to $0.7 \mathrm{pu})$ can be selected such that the line capacitor size can be increased accordingly to improve the input current waveform.

The second step is to determine the line side capacitor. This could be accomplished graphically using a plot similar to Fig. 5, from which the line capacitor size can be selected.

\section{Experimental Results}

Table 2 shows some of the experimental results from a $208 \mathrm{~V}, 5 \mathrm{hp}$ GTO current source induction motor drive with a fan type load of load. According to the design steps discussed above, a line capacitor of 0.4 can and motor capacitor of $0.67 \mathrm{pu}$ are selected. The input power factor of the drive with $100 \%$ and $30 \%$ of rated load is 0.96 (leading) and 0.98 (lagging), respectively. Since the line current is close to sinusoidal, distortion factor is neglected and only the displacement factor is considered here. Figure 6 illustrates the waveforms of the source voltage $V_{s}$, source current $I_{s}$ and rectifier input current $I_{w}$ with two different loadings. It can be seen that under the rated load condition, the system input power factor is leading. When the drive operates at $30 \%$ of the rated load, a slightly lagging power factor is observed.

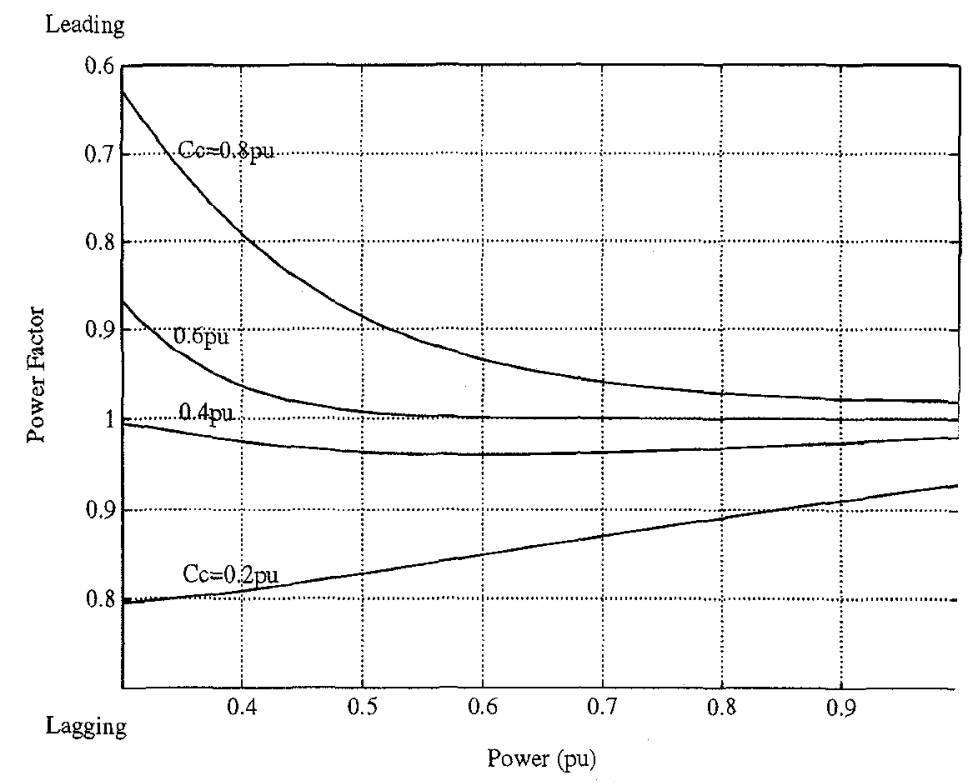

Fig. 4 Input power factor of drive with fan/pump loads $\left(C_{i}=0.6 \mathrm{pu}\right.$, assuming motor power factor is unity)

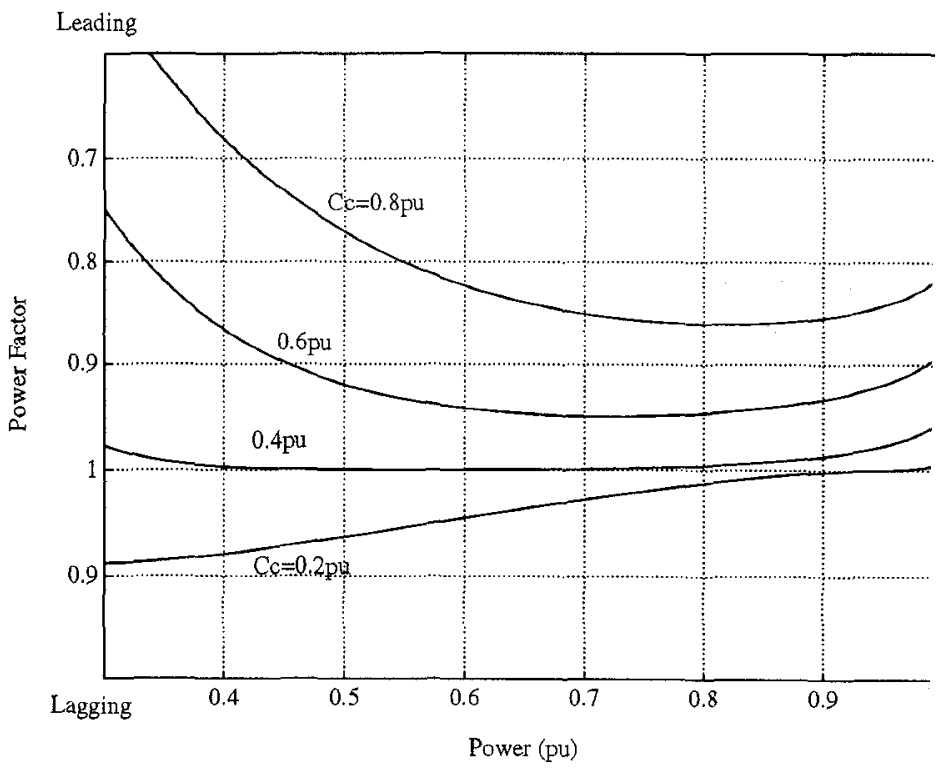

Fig. 5 Input power factor of drive with fan/pump loads $\left(\mathrm{C}_{\mathrm{i}}\right.$ $=0.6 \mathrm{pu}$, motor rated power factor $=0.9$ )

\section{Conclusions}

The input power factor of GTO PWM current source rectifiers using a delay angle control scheme is investigated. It is discovered that with an optimal design of line and motor side capacitors for CSR-CSI induction motor drives having fan/pump loads, the input power factor is close to unity ( over 0.95 for $30 \%$ to $100 \%$ of rated load ). The concept of near unity power factor operation is presented. The procedures for the capacitor design are discussed. A switching pattern suitable for the delay angle control with a low harmonic distortion is also introduced. The line current 
Table 2 Experimental results from a 5hp induction motor drive system

\begin{tabular}{||c|c|c|c|c|c||}
\hline $\mathrm{P}_{\text {oul }}(\mathrm{pu})$ & 0.31 & 0.43 & 0.64 & 0.79 & 1.0 \\
\hline$\omega_{\text {motor }}(\mathrm{pu})$ & 0.68 & 0.76 & 0.86 & 0.93 & 1.0 \\
\hline $\mathrm{PF}_{\text {motor }}$ & 0.57 & 0.60 & 0.72 & 0.75 & 0.79 \\
\hline $\mathrm{PF}_{\text {input }}$ & 0.98 (lagging) & 1.0 & 0.99 (leading) & 0.99 (leading) & 0.96 (leading) \\
\hline
\end{tabular}

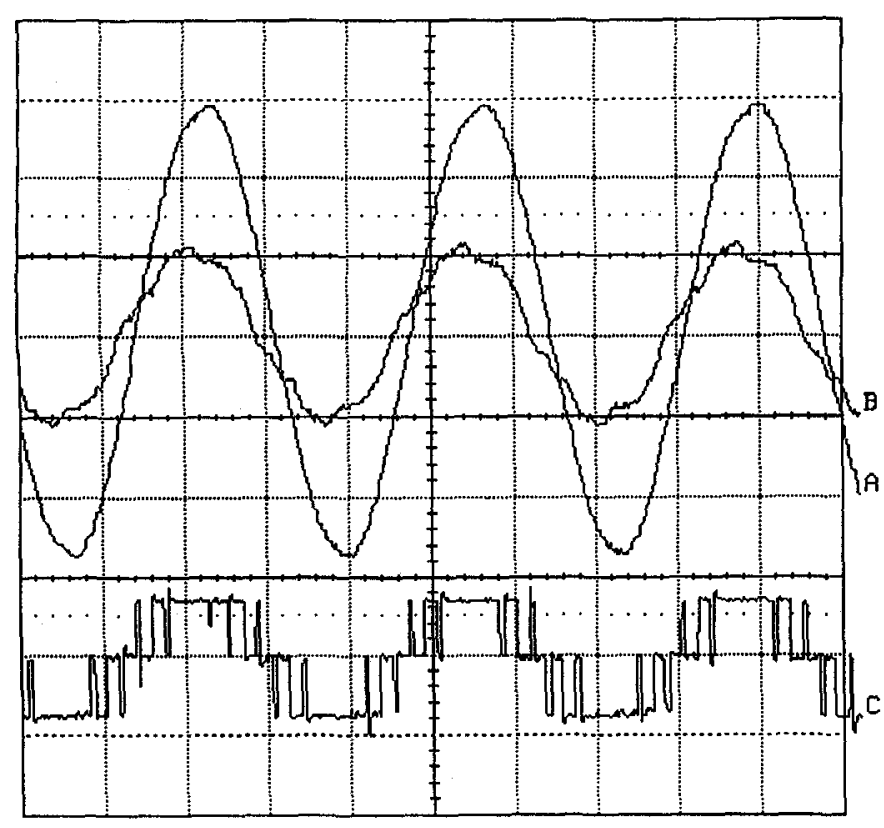

(a) Rated load

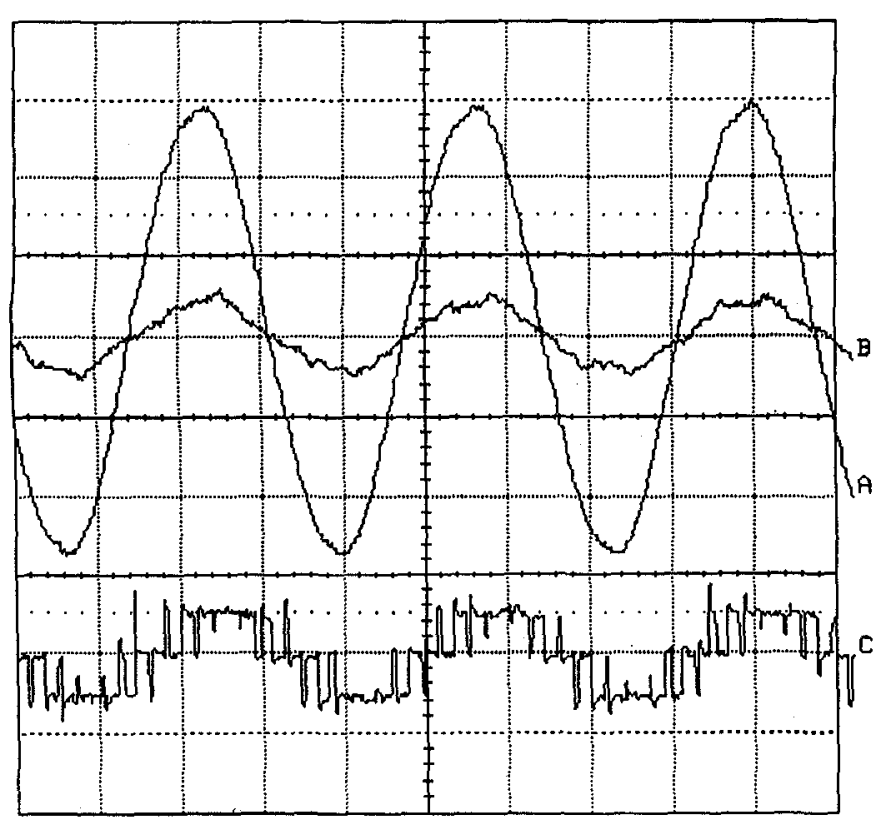

(b) $30 \%$ of rated load

Trace A: Line-to-neutral voltage $50 \mathrm{~V} / \mathrm{div}$

B: Line current $I_{s} \quad 20 \mathrm{~A} / \mathrm{div}$

C: Rectifier current $I_{w} \quad 20 \mathrm{~A} / \mathrm{div}$

Fig. 6 Experimental results from a 5 hp induction motor drive of the rectifier is near sinusoidal due to the use of the switching pattern and line side capacitor. Experimental results on a $5 \mathrm{hp}$ drive are given to verify the theoretical analysis.

\section{Reference:}

[1] B. Wu, S. A. Dewan and G. R. Slemin, "PWM-CSI inverter for induction motor drives," IEEE Trans. IA., 1992, pp64-71.

[2] P. M. Espelage, J. M. Nowak, " Symmetrical GTO current source inverter for wide speed range control of 2300 to 4160 volt, 350 tp 7000 hp, induction motors," IEEE IAS Annual Meeting, pp302-307, 1988.

[3] M. Iwahori and K. Kousaka, " Three-phase current source rectifier adopting new PWM control techniques," IEEE IAS Annual Meeting, 1989, pp.855860.

[4] H. R. Karshenas, H. A. Kojori and S.B. Dewan, "Generalized techniques of selective harmonic elimination in rurrent source inverters/converters," IEEE Trans. IA., 1995, pp566-573.

[5] J.H. Choi, H.A. Kojori, and S.B. Dwan, " High power GTO-CSC based power supply utilizing SHE-PWM and operating at unity power factor," CCECE, 1993.

[6] Y. Xiao, B. Wu, S. Rizzo and R. Sotudeh, "A novel power factor control scheme for high power GTO current source converter," IEEE IAS Annual Meeting, 1996 ( to be published ). 